\title{
Cacuriá: Uma Ferramenta de Autoria Multimídia para Objetos de Aprendizagem
}

\author{
André Luiz de B. Damasceno', Thacyla de Sousa Lima ${ }^{1}$, Antônio José Grandson \\ Busson $^{1}$, Carlos de Salles Soares Neto ${ }^{1}$ \\ ${ }^{1}$ Departamento de Informática - Universidade Federal do Maranhão (UFMA) \\ Av. Dos Portugueses, 1966. Bacanga - CEP 65080-805. São Luís - Maranhão - Brazil \\ \{andrelbd1, thacyla.sl, ajgbusson\}@gmail.com, csalles@deinf.ufma.br
}

Resumo. Hoje em dia é muito comum o uso de Objetos de Aprendizagem (OAs) tanto na educação presencial quanto na educação a distância. Isso tem tornado o processo de aprendizagem mais participativo e interativo. Contudo a autoria de OAs mais elaborados ainda é um processo complexo e demorado. O objetivo deste trabalho é apresentar o Cacuriá, uma ferramenta que visa facilitar a criação de OAs por educadores. Por último, um estudo de caso foi conduzido para demonstrar o processo de autoria de conteúdo pela ferramenta, sem que o usuário necessite de conhecimentos prévios de programação.

\section{Introdução}

O processo de ensino e aprendizagem está em constante evolução, e como podemos ver nos dias atuais, professores e alunos estão cada vez mais usando tecnologias que apoiem tal processo. O uso de materiais de apoio como tablets, slides, vídeos e jogos tem se tornado uma tendência tanto no ensino presencial quanto no ensino a distância. Um recurso multimídia recorrente nesse contexto é o emprego de objetos de aprendizagem ou OAs.

Wiley (2000) e IEEE (2012), objetos de aprendizagem são definidos como qualquer entidade, digital ou não, quer pode ser utilizada, reutilizada ou referenciada durante o aprendizado ou treinamento apoiado por computador. Tais objetos tem como principal função atuar como recurso didático, englobando determinado conteúdo de uma disciplina e podendo utilizar recursos multimídia como imagem, texto, vídeo. Essas características tem mostrado que o uso OAs, como ferramenta de apoio por educadores, tem facilitado e melhorado a qualidade do ensino (Betio e Martins 2012) (Miller 2011).

Entretanto a produção de objetos de aprendizagem não é um processo simples. Geralmente é necessária uma equipe de profissionais de diferentes áreas de conhecimento para a elaboração de OAs. Isso pode acarretar em maior tempo de desenvolvimento e num alto custo de produção. Essa equipe é composta por programadores para codificarem OAs complexos, designers para estabelecer uma identidade visual, pedagogos para traçar e medir objetivos didáticos, além de contar com um a presença de um professor conteudista que detém o conhecimento do assunto.

O objetivo deste trabalho é apresentar a ferramenta de autoria multimídia Cacuriá e o seu método de criação de OAs. Através desta ferramenta, o professor tem a possibilidade de construir OAs baseados em vídeos para Web e TV Digital Interativa, sem a necessidade de conhecimento prévio de programação e design. A ferramenta 
Cacuriá faz uso do sincronismo temporal de mídias e as organiza através da metáfora de cena, onde cada vídeo que compõe seu OA é referenciado na própria cena.

O artigo está organizado como segue. A Seção 2 descreve os trabalhos relacionados. A Seção 3 descreve a ferramenta Cacuriá. A Seção 4 descreve o estudo de caso. A Seção 5 descreve as considerações finais.

\section{Trabalhos Relacionados}

Foram encontradas diversas ferramentas de autoria para a produção de OAs. Pode-se citar como principais: CourseLab (http://www.courselab.com); DITV-Learning (Neto e Bezerra 2012); eXe Learning (http://www.exelearning.org); HotPotatoes (http://hotpot.uvic.ca); Microsoft LCDS (http://www.microsoft.com/learning/en-us/lcdstool.aspx); MARKER (Sousa 2013). A maioria dessas ferramentas seguem como modelo de referência o SCORM (SharableContentObjectReferenceModel), que é um conjunto de especificações que define um modelo de agregação de conteúdo, de sequenciamento e execução para objetos de aprendizagem baseados na Web (ADL 2012).

O CourseLab é um software com interface semelhante ao Microsoft PowerPoint. Utiliza a abordagem WYSIWYG (WhatYouSeeIsWhatYouGet) a fim de facilitar a criação de OAs pelo usuário. A ferramenta suporta diversos formatos de arquivo como vídeo, áudio, texto, appletJava, flash, entre outros. Ela também permite a programação de ações entre objetos, como por exemplo, ao clicar em determinada animação, a ferramenta gera ações como informar um texto na tela. Contudo ela não permite a edição do HTML dos objetos de aprendizagem. A ferramenta permite também a criação de atividades interativas como: única e múltipla escolha; verdadeiro e falso; ordenação de itens; preenchimento de lacunas nas frases; e correspondência de itens. Além disso, seu conteúdo pode ser executado em AVAs (Ambientes Virtuais de Aprendizagem) como Moodle, ATutor, Oracle iLearning e etc.

O DITV-Learning é uma ferramenta para automatizar a criação de OAs para a TVDI por educadores que possuam pouco conhecimento em informática. A ferramenta é uma aplicação desktop que suporta arquivos do tipo vídeo, áudio, imagem e texto. $\mathrm{O}$ DITV-Learning permite aos usuários criarem perguntas após o vídeo principal, indicando acertos e erros (quiz), conteúdo em forma de slides (bônus) e complementos que podem ser acionados de forma interativa durante a aplicação (extra). O OA gerado pela ferramenta é exibido somente em dispositivos com o middleware Ginga NCL.

$\mathrm{O}$ eXe Learning é uma Ferramenta Web destinado para a criação de OAs em HTML, que também pode ser utilizado em AVAs. A ferramenta disponibiliza aos usuários recursos interativos como texto de leitura, questões de múltipla escolha, questões de verdadeiro ou falso, applet Java, vídeos do youtube e artigos WikiBooks. Na ferramenta de autoria há sete templates editáveis, um OA que descreve como utilizar a ferramenta, criação de iDevices, além de ser permitida a edição do HTML dos OAs.

O Hot Potatoes é uma ferramenta desktop destinada para a produção de exercícios interativos em AVAs, sendo reconhecido automaticamente pelo Moodle. Ele é composto por cinco tipos de atividades interativas: quiz; preenchimento de lacunas; correspondência; palavras cruzadas; e ordenação de palavras no texto. Ao criar uma atividade é possível inserir perguntas e respostas, porém não é possível utilizar 
animações. Seus recursos são disponíveis para uma única página, porém a ferramenta permite agrupar diversas atividades em um único pacote.

O LCDS é a ferramenta desktop da Microsoft para criação de OAs. A ferramenta suporta arquivos do tipo texto, imagens e vídeo e ainda conta com templates para autoria de OAs. Ela permite a produção em sequência de páginas, porém não permite a alteração do tamanho das páginas. O OA em formato HTML gerado pelo LCDS não é passível de edição e nem produzido no formato SCORM. A ferramenta também disponibiliza ao usuário um manual do software na língua inglesa.

O MARKER é uma ferramenta desktop que, como o DITV-Learning, é destinada para autoria de OAs para a TVDI que possuam middleware Ginga NCL. Ela permite ao usuário criar marcações no vídeo principal e em seguida selecionar a mídia a ser inserida nos marcadores, como forma de implantar um momento de interação. $\mathrm{O}$ MARKER suporta arquivos do tipo vídeo, imagem, áudio e texto.

\section{Cacuriá}

O Cacuriá é uma ferramenta de autoria destinada à criação de OAs para a TVDI e Web. Ele é desenvolvido em linguagem de programação $\mathrm{C}++$, com a utilização do framework Qt (Blanchete e Summerfield 2008). Esse framework permite a criação de aplicativos multiplataforma utilizando a abordagem "escreva uma vez, compile em qualquer lugar" (Blanchete e Summerfield 2008), que viabiliza a instalação da ferramenta em diferentes sistemas operacionais.

A interface da ferramenta é composta por seis visões para manipulação das mídias conforme podemos observar na Figura 1. A Visão de Menu (1) é usada para adição de mídias e cenas, remoção de cenas, visualização do projeto e publicação do OA. A Visão de Cenas (2) é usada para visualização das cenas e indicar qual a cena em foco. A Visão de Leiaute (3) é usada para visualização do posicionamento e dimensionamento da mídia de acordo com tempo. A Visão Temporal (4) é usada para executar e manipular o tempo da cena. A Visão de Propriedades (5) é usada para visualização e edição das propriedades da mídia em foco. Por sua vez, a Visão de Biblioteca (6) é usada para listar as mídias da cena atual.

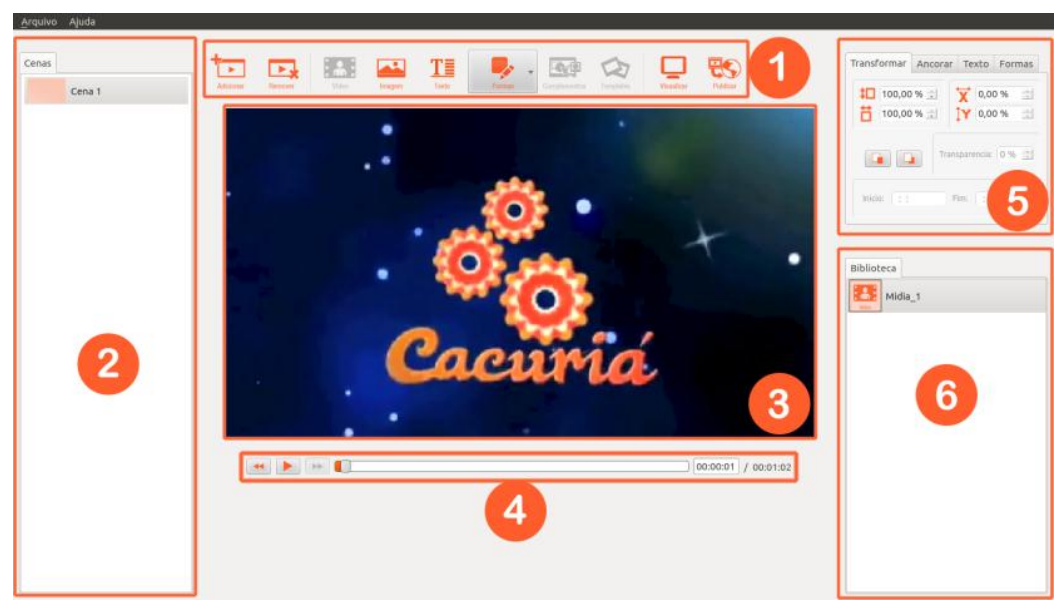

Figura 1: Interface do Cacuriá. 
A abordagem utilizada na ferramenta é WYSIWYG (WhatYouSeeIs WhatYouGet), em que o conteúdo visto e que está sendo modificado é idêntico à aplicação final gerada pela ferramenta. Assim, o uso dessa ferramenta não exige dos usuários conhecimentos prévios sobre detalhes da linguagem de especificação para desenvolver aplicações interativas. Isso se mostra particularmente útil aos usuários comuns, sem conhecimentos específicos de programação, que estejam interessados em produzir OAs. Pode ser também usado pelo usuário casual, que não quer ou não pode desprender tempo a aprender uma linguagem ou tecnologia somente para esse propósito.

A abstração utilizada pela ferramenta para criação dos OAs é chamada de Cena. Cada cena é composta por um vídeo principal e outros tipos de mídia (imagem, texto, formas) sincronizadas com o vídeo. Podem haver também links entre as cenas que são acionadas por botões, tornando o conteúdo interativo e não linear. O Cacuriá conta também com o uso de Templates de Cenas, onde já estão pré-definidas as interações entre as mídias da cena e deixando que o usuário fique apenas com a tarefa de escolha das mídias que serão usadas nesse template. Além disso, existe a possibilidade de adição de Complementos como quiz e marcadores temporais, para deixar o conteúdo ainda mais interativo.

A ferramenta possui um módulo de processamento interno responsável pelaconversão de aplicações Cacuriá em código NCL (Nested Context Language) ou HTML5. NCL é a linguagem de programação adotada pela ISDB-Tb (International Services for Digital Broadcast, TerrestialBrazilian) para especificação de aplicações interativas na parte declarativa de seu middleware Ginga, assim como o ITU-T (InternationalTelecommunication Union) a definiu como recomendação para serviços IPTV. HTML 5 é a linguagem de marcação para estruturação e apresentação de conteúdo para a World Wide Web, o que possibilita a execução dos OAs produzidos no Cacuriá em AVAs que permitem adição desse tipo de aplicação.

\section{Estudo de Caso}

Nesta seção é apresentada a construção de um OA com a temática de algoritmos utilizando a ferramenta Cacuriá. Como pode ser visto na Figura 2, o OA consiste em um vídeo onde um professor apresenta uma introdução a algoritmos de ordenação. Em um determinado momento desse vídeo, é oferecida ao aluno a escolha entre dois algoritmos específicos: insertsort ou quicksort. A partir disso, o vídeo corrente é redirecionado para um novo vídeo sobre o assunto referente ao algoritmo escolhido pelo aluno.

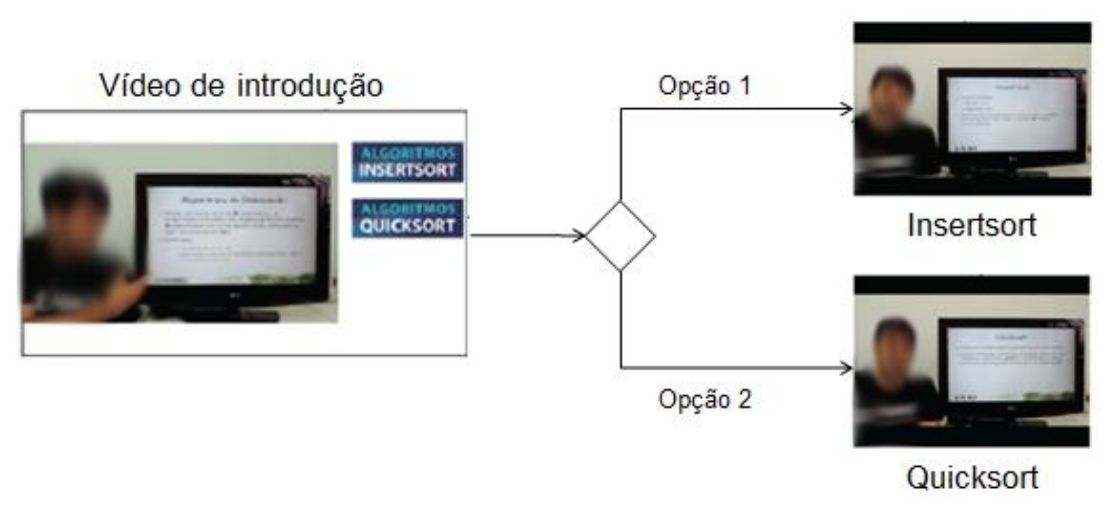

Figura 2: OA de Algoritmos de Ordenação 
Quando iniciada, a ferramenta Cacuriá já possui uma cena incorporada, a Cena 1. Para construção do objeto, é inserido nessa cena um vídeo, "Introdução.mp4". Isso é feito pressionando o botão "Vídeo" situado na Visão de Menu, o que desencadeia a abertura de uma janela de navegação onde o usuário deverá indicar o local em que se encontra o vídeo a ser inserido. Como mostra a Figura 3, quando adicionado, o vídeo passa a ter uma representação na Visão da Biblioteca, seu primeiro frame é apresentado na Visão de Leiaute, a opção de inserir um vídeo fica desabilitada e torna-se possível inserir as outras mídias: imagem, formas e texto. Além disso, os campos da aba "Transformar" da Visão de Propriedades são disponibilizadas para manipulação, permitindo a alteração do dimensionamento e posicionamento do vídeo. Essa manipulação também pode ser feita através do mouse, usando a alça de redimensionamento que a mídia possui na Visão de Leiaute.
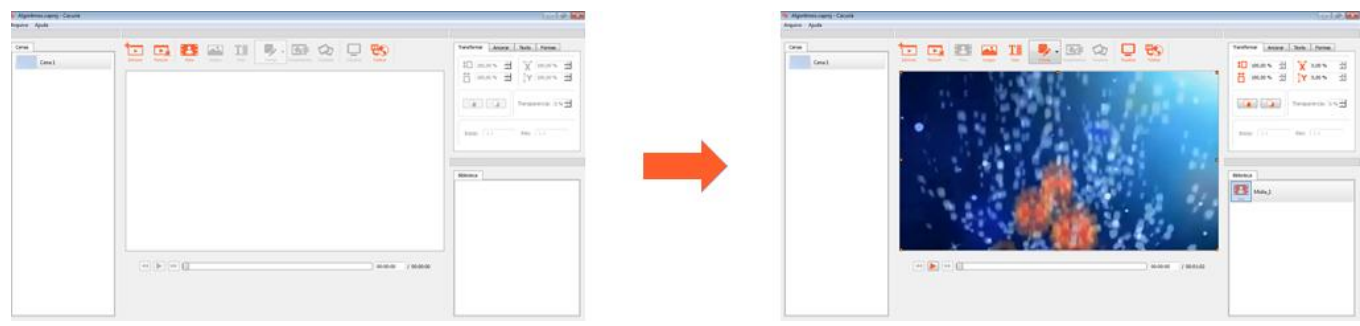

Figura 3: Interface do Cacuriá após a inserção do vídeo.

Aos 57 segundos do vídeo "Introdução.mp4", base da Cena 1, o professor questiona o aluno sua opção para continuar o OA. Nesse instante de tempo o vídeo é redimensionado e posicionado para o lado esquerdo da tela e são adicionadas à Cena 1 duas imagens, "Insertsort.png" e "Quicksort.png", que posteriormente serão utilizadas para fazer os links com outras cenas. Uma mídia de imagem é incorporada à cena quando o ícone "Imagem", encontrado na Visão de Menu, é clicado. Assim como no vídeo, após o clique no ícone "Imagem" é aberta uma janela de navegação utilizada pelo o usuário para indicar o local onde está a imagem desejada. A inserção das mídias de imagem, de formas e de texto só pode ser feita com a cena pausada, por isso, a Cena 1 é pausada aos 57 segundos para a adição das imagens. As imagens são, então, redimensionadas e posicionadas usando a alça de redimensionamento ou manipulando as propriedades da aba "Transformar", resultando na disposição mostrada na Figura 4.

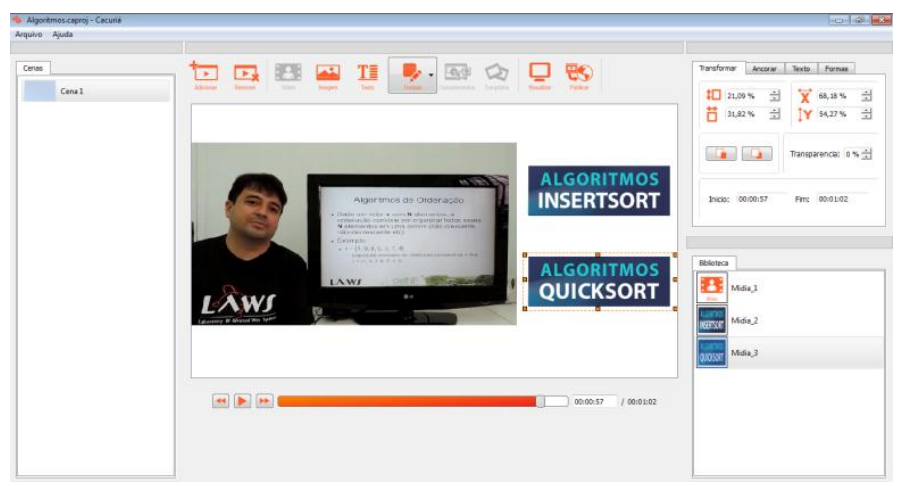

Figura 4: Interface do Cacuriá após o posicionamento das imagens. 
No desenvolvimento desse objeto são utilizados três vídeos e como na ferramenta cada cena possui apenas um vídeo, são adicionadas mais duas cenas. A adição de uma cena é feita clicando sobre o ícone "Adicionar" encontrado na Visão de Menu. Com a inserção de uma cena, essa passa a ter uma representação na Visão de Cenas. Para a construção da Cena 2, é preciso selecioná-la na Visão de Cenas. Com isso, torna-se possível inserir o vídeo sobre o algoritmo Insertsort, "Insertsort.mp4", conforme mostra a Figura 5. Novamente, através das listas de cenas, seleciona-se a Cena 3. Nessa cena, é inserido o vídeo explicativo sobre Quicksort, "Quicksort. mp4”, o que pode ser visto na Figura 6.

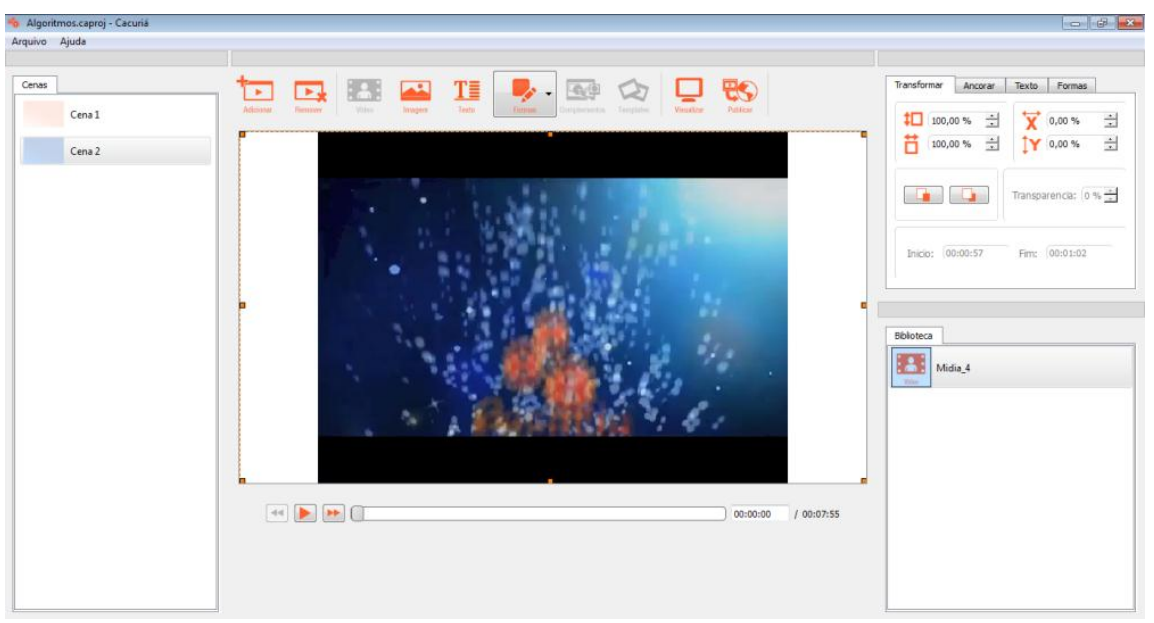

Figura 5: Interface do Cacuriá após adicionar o vídeo na Cena 2.

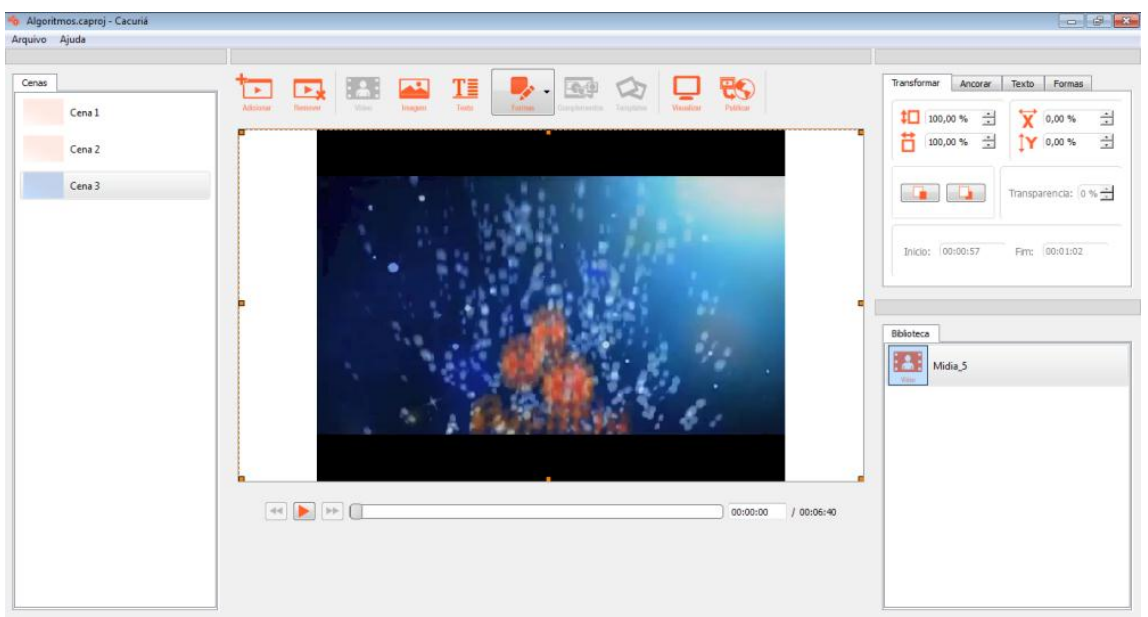

Figura 6: Interface do Cacuriá após adicionar o vídeo na Cena 3.

Com as três cenas construídas, o OA em desenvolvimento é finalizado com a configuração dos links entre as cenas. Na ferramenta Cacuriá, os links podem ser feitos através de imagens, formas e texto. No caso do exemplo do OA em construção, os links são feitos utilizando as imagens "Insertsort.png" e "Quicksort.png" da Cena 1. Quando a imagem é selecionada, os campos "Ir para Cena", "Início da Cena" e "Tecla" da aba "Ancorar" localizada na Visão de 
Propriedades são habilitados para edição. O campo "Ir para Cena" oferece uma lista com as cenas existentes. O campo "Início da Cena" determina para qual instante de tempo, a cena escolhida na opção "Ir para Cena", é iniciada. O campo "Tecla" apresenta as teclas de atalho que podem ser utilizadas no link de uma cena. Para a imagem "Insertsort.png", foram definidas as opções Ir para Cena 2, iniciar no tempo de zero segundos e utilizar como atalho a tecla "1", como pode visto nas Figura 7 e 8. Já para a imagem "Quicksort.png", foram definidas as opções Ir para Cena 3, iniciar no tempo de zero segundos e utilizar como atalho a tecla " 2 ", como pode ser observado nas Figuras 9 e 10.

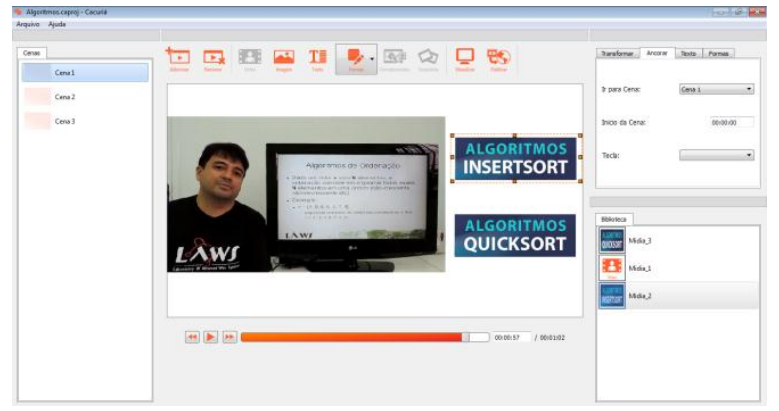

Figura 7: Interface do Cacuriá.

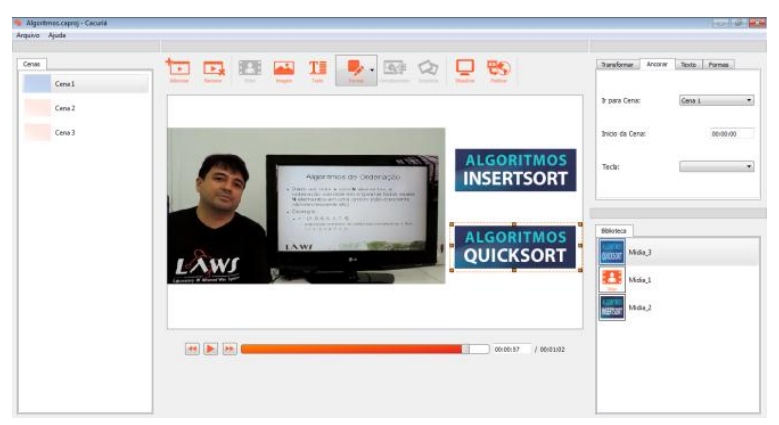

Figura 9: Interface do Cacuriá.

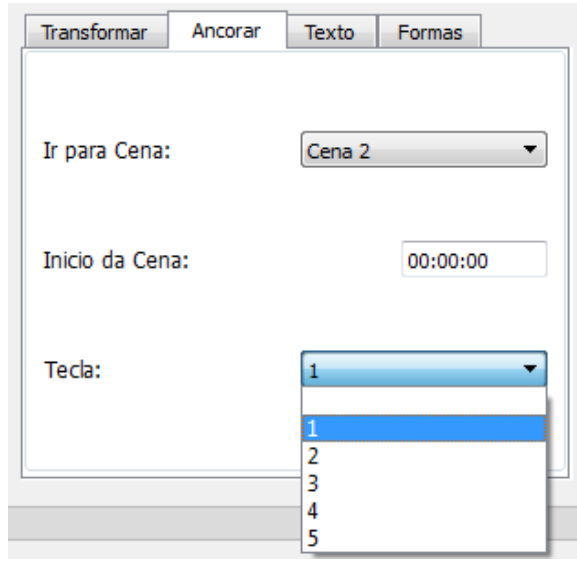

Figura 8: Propriedades da aba "Ancorar".

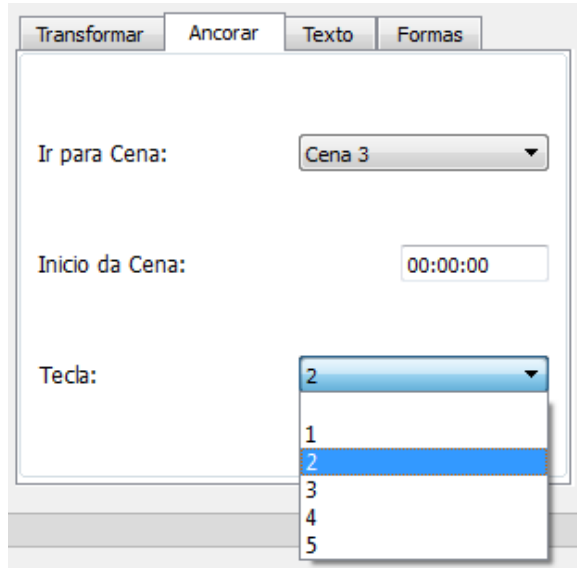

Figura 10:Propriedades da aba "Ancorar".

Com a construção desse OA de algoritmos, é possível visualizar alguns dos recursos disponíveis na ferramenta Cacuriá. A utilização dos links entre as cenas para definir o caminho que o OA deve seguir, de acordo com a escolha do aluno, caracteriza a autoria não-linear. O exemplo permite também observar como funciona a abstração de cenas e como as mídias são sincronizadas de acordo com o tempo do vídeo da cena, como foi feito com a adição das imagens "Insertsort.png" e "Quicksort.png". Percebe-se a facilidade para inserir mídias, usando a "Visão de Menu", e manipular suas propriedades, utilizando suas alças de redimensionamento e a "Visão de Propriedade". 


\section{Considerações finais}

O estudo realizado mostra avanços tecnológicos no contexto educacional, marcado pelo surgimento de novos paradigmas de ensino e de interação entre professores e alunos. Neste cenário o uso de objetos de aprendizagem tem demonstrado ser eficiente no aperfeiçoamento do processo de ensino e aprendizagem. Este trabalho apresenta o Cacuriá, uma ferramenta de autoria para o desenvolvimento de OAs para TVDI e Web, por educadores sem a necessidade de conhecimento em programação.

A ferramenta de autoria Cacuriá utiliza a metáfora de cenas para a criação de OAs. Apesar da ferramenta ainda estar em desenvolvimento, o estudo de caso demonstrou que já é possível construir objetos de aprendizagem com a ferramenta. $\mathrm{O}$ Cacuriá vem sendo utilizado por algumas instituições de ensino presencial e à distância, que utilizam OAs em suas metodologias de ensino.

Como trabalho futuro, planeja-se implementar mais módulos que facilitem o processo de criação de OAs. Além disso, a visão futura para a ferramenta Cacuriá é a de que ela se torne um ambiente integrado tanto para a autoria de OAs quanto para o compartilhamento deles com os alunos. É interessante tornar o OA passível de compartilhamento e reuso, para que outros educadores tenham a liberdade de aprender, modificar e melhorar o conteúdo.

\section{Agradecimentos}

O presente trabalho foi realizado com o apoio financeiro da FAPEMA e RNP, entidades do governo brasileiro voltada para formação de recursos humanos.

\section{Referencias}

ADL - Advanced Distributed Learning (2012) "SCORM", http://adlnet.org/scorm/, Junho.

Betio, R. W. e Martins, A. (2002), Objetos de aprendizado: um novo modelo direcionado ao ensino a distância. In $9^{\circ}$ Congresso Internacional de Educação a Distância.

Blanchete, J. e Summerfield, M. (2008), C++ GUI.Programming with Qt 4.Prentice Hall.

IEEE (2012), "Draft standard for learning object metadata", Learning Technology Standards Committee.

Miller, L. D. et al. (2011). Evaluating the Use of Learning Objects in CS1. In $A C M$ Technical Symposium on Computer Sience Education.

Neto, F. A. S. e Bezerra, E. P. (2012), "DITV-Learning: Uma Ferramenta de Autoria à Criação de Objetos Digitais de Aprendizagem para Televisão Digital Interativa." In $23^{\circ}$ Simpósio Brasileiro de Informática na Educação.

Sousa, S. W. F. et al. (2013). MARKER: A Tool for Building Interactive Applications for T-Learning. In $19^{\circ}$ Simpósio Brasileiro de Sistemas Multimidia e Web.

Willey, D. A. (2000), "Connecting learning objects to instructional design theory: A definition, a metaphor, and a taxonomy”, http://reusability.org/read/\#1, Junho. 